\title{
The Threshold between the Material and Immaterial Light. Notes on Luminescence and Dark Environments
}

\author{
Ana Margarida Rocha ${ }^{1,2, *}$, Teresa Almeida ${ }^{1,2}$ and Graciela Machado ${ }^{1,2}$ \\ 1 Faculdade de Belas Artes, Universidade do Porto, 4049-021 Porto, Portugal; talmeida@fba.up.pt (T.A.); \\ mgmachado@fba.up.pt (G.M.) \\ 2 VICARTE, Research Unit "Glass and Ceramics for the Art", Faculdade de Ciências e Tecnologia, \\ Universidade NOVA de Lisboa, 2829-516 Monte da Caparica, Portugal \\ * Correspondence: anamargaridarocha.fbaup@gmail.com
}

check for updates

Citation: Rocha, Ana Margarida, Teresa Almeida, and Graciela Machado. 2021. The Threshold between the Material and Immaterial Light. Notes on Luminescence and Dark Environments. Arts 10: 56. https://doi.org/10.3390/arts10030056

Academic Editor: Thor J. Mednick

Received: 4 June 2021

Accepted: 13 August 2021

Published: 20 August 2021

Publisher's Note: MDPI stays neutral with regard to jurisdictional claims in published maps and institutional affiliations.

Copyright: (c) 2021 by the authors. Licensee MDPI, Basel, Switzerland. This article is an open access article distributed under the terms and conditions of the Creative Commons Attribution (CC BY) license (https:// creativecommons.org/licenses/by/ $4.0 /)$.

\begin{abstract}
This article discusses the phenomenon of luminescence in the production and visualization of images from an art-practice standpoint. The theoretical argument is developed through an analysis of artistic work that explores, inserts, expands, articulates, and interrogates the internal contradictions of UV light and the transitivity of light-sensitive materials in installation contexts. This investigation explores complexities in the encounter of antagonistic concepts: the threshold phenomena between materiality and immateriality, visibility and invisibility, light and darkness, disclosure and concealment. It aims to articulate a new perspective on contemporary debates on physiological, psychological, and environmental effects of light and darkness, articulated through aesthetic experience and artistic practice. Methods for engaging in the sensation of light and darkness will be introduced and how it unfolds as experiential qualities within installation projects will be considered.
\end{abstract}

Keywords: light; dark; UV light; luminescence; sodalite zeolite; light emission

\section{Introduction}

Sensitivity to light is a universal attribute for most living organisms. According to Oxford zoologist Andrew Parker's Light Switch Theory (Parker 2003), eyes first appeared approximately 543 million years ago, during the Cambrian era, and light was the trigger. At that time, the chemistry of the oceans and the atmosphere changed. They became much more transparent. Suddenly, it was beneficial to have sight organs able to provide information about the surrounding environment, either to see prey or predators. This new perceptual ability promoted distal senses over proximal ones, and a drastic natural selection process solidified this new hierarchy. Organisms had to adapt and evolve to prosper within visible environments; the eyes thus "developed from light-sensitive spots on the surface of simpler animals" (Gregory 2015, p. 27).

Vision is subject to light. Based on our daily sensory experience, we are able to interact with objects present in an environment because we are surrounded by a transparent medium - the air, the atmosphere-together with the contingent presence of light. Our visual system is able to locate and interpret the light that reaches our eyes through photoreceptor cells found in the retina: rod cells, cone cells, and photosensitive ganglion cells, transducing light to neural signals (Buser et al. 1992; Bruce et al. 2014; Gregory 2015).

Light impacts our daily life. It fills our eyes, bathes our skin, nourishes our food and our habitats, makes us see and be amazed. Our biorhythms are in tune with the natural changes of light (Wetterberg 2014), marked by the alternation of day and night, light and darkness, wakefulness and sleep. According to its intensity and spectral composition, light determines our colour perception of the objects and surfaces within a space and also is able to induce specific emotional states, performances, and behaviours and activate specific cognitive skills within the perceiver (Flynn 1977; Flynn et al. 1979; Boyce 2014). 
Ambient light and the physical aspects of light that are relevant to the perceiver in the environment were widely researched by American psychologist J. J. Gibson. He considered the senses to be perceptual systems (Gibson 1966) and promoted ecological psychology and ecological optics (Gibson 1979), arguing that visual perception is about extracting information from the structure of light and its modulations, and that what we perceive is the stimulation of light on us, not light itself. He made a distinction between radiation and illumination: radiation is emitted from a source; illumination lights up the world. Radiation, principally from the sun, becomes illumination by being scattered in all directions, by refraction through particles in the atmosphere and reflection by the mottled and textured surfaces of the earth.

In fact, light and eyes are not sufficient for the experience of light. These apparent forms of light depend on the material encountered by the light and the material's surface properties. Patterns of light are structured by surfaces. Our aesthetic encounters are mediated on the surface, as posited by Bruno (2014) in a critical investigation on the surface that incorporated the relationship of materiality with aesthetics, technology, and temporality. Bruno argues that visual experience also manifests materially, on the surface of things, and that surfaces can be understood as "the material configuration of the relation between subjects and with objects ( . . ) ), a site of mediation and projection" (Bruno 2014, p. 3).

We perceive in conformity with the light and, in a way, light anticipates our vision. As Merleau-Ponty argues, light may be sensed as the "correlation between appearances and our kinaesthetic unfoldings, something not known through a law, but experienced as the involvement of our body in the typical structures of a world" (Merleau-Ponty 2002, p. 361). The work of the French philosopher is marked by the persistent argument for the foundational role of perception not only in the process of understanding the world, but also in our constant engagement with it. Light is understood by Merleau-Ponty not as radiant energy but as an embodied experience. He emphasizes the simultaneous participation of multiple physiological and psychological factors in the processes of perception, a process that takes on creative receptivity and not a passive capacity to receive impressions, an activity inseparable from its corporeality.

Light is perceived by the body and affects the way we understand and engage with the world. It does not merely illuminate, but actually performs a mediating function between the viewers and the space. This makes light a medium. The use of light as an artistic medium is intrinsically tied to viewer's sensory experience. In Installation Art: A Critical History, Claire Bishop defines installation as a type of art that "the viewer physically enters, and which is often described as theatrical, immersive or experiential" (Bishop 2005, p. 6). Bishop suggests that this type of work has the purpose of heightening the viewer's awareness of how objects are positioned in space and our bodily response to this, introducing the concepts of activation and decentring. Instead of representing, installation presents elements such as light directly for us to experience.

The human eye can be challenged, manipulated, or deceived through the interaction of artificial and natural light upon different objects, materials, and surfaces. Perception and the subjective and physiological effects of light on subjects were among the primary interests of the Light and Space movement of the 1960s and 1970s. Artists such as James Turrell, Robert Irwin, Dan Flavin, Bruce Nauman, and Doug Wheeler demonstrated how the use of technical and industrial advances in lighting devices could expand the boundaries of art practice and stimulate heightened sensory awareness in the receptive viewer. They applied mechanical and psychological effects of visual and haptic perception "whether by directing the flow of light, embedding artificial light within objects or architecture, or playing with light through the use of reflective, translucent, or transparent materials" (Clark 2011, p. 20).

James Turrell selected light as a primary medium for his work during the 1960s. As the artist puts it, "My material is light, and it is responsive to your seeing" (Adcock and Turrell 1990, p. 114). In his work, he deals with perceptual environments directly, giving form to perception and disclosing light's own presence and power for the viewer. The basic 
characteristics of electromagnetic flux can be seen directly in his Projection Pieces, such as Afrum (White) (1966), in which light itself becomes substantive. A visual experience of the haptic realm is given to the viewers "as it they could feel light with their eyes, like pressure on the skin of visual perception" (Adcock and Turrell 1990, p. 2).

\section{UV Light, Almost Nothing to See?}

The phenomenon of light-its intensity, wavelength, distribution, reach, or absenceis an active part of art practice and art experience. Museum specialist Michael Katzberg argues, in Cultures of light: contemporary trends in museum exhibition, that the application of various wavelengths of light enhances the viewer's sensorial experience and, particularly, that "blacklight is increasingly being used in many museum exhibitions for a variety of purposes" (Katzberg 2009, p. 97).

Blacklight is a generic term related to the physical phenomenon of ultraviolet (UV) radiation. UV radiation was discovered in 1801 by German physicist Johan Wilhelm Ritter. The discovery was based on his observation that invisible rays just beyond the violet end of the visible spectrum, which he called "oxidizing rays," darkened silver chloride-soaked paper more quickly than violet light itself (Beeson and Mayer 2007; Pachuau and Tiwari 2008; Frercks et al. 2009; Ahmad 2017).

The sun's radiation covers a wide band of wavelengths, from short to long, from ultraviolet to infrared, although what reaches the earth is by no means the whole electromagnetic spectrum. Most of the ultraviolet is absorbed by the atmosphere. Our eyes are sensitive to a very narrow part of the electromagnetic spectrum, the visible light spectrum, with wavelengths ranging from 400 nanometres to 700 nanometres (Buser et al. 1992; Beeson and Mayer 2007). Ultraviolet (UV) light, on the other hand, varying in its wavelength from $100-400 \mathrm{~nm}$, is divided into three bands: UVA $320-400 \mathrm{~nm}$, UVB $290-320 \mathrm{~nm}$, and UVC 180-290 nm (Ahmad 2017). This means that the human eye is unable to see this type of radiation.

Blacklight contains a paradox in itself: How can light be black? Is this not a contradiction? The first half of the word refers to darkness and the second half to clarity, two different meanings that can cancel each other out. Light has intrinsically positive qualities. It discloses information and makes objects observable, whereas darkness hides, conceals, obscures them. Blacklight is thus an oxymoron in word and concept. Blacklight is not light in the usual sense of the word because it emits little luminous intensity in the visible range (Pachuau and Tiwari 2008). Ultraviolet radiation is invisible to the human eye. Illuminating certain materials with UV lighting, however, causes these substances to glow with various colours, in turn emitting visible light. This is called luminescence, a phenomenon that we will develop further below.

Sources of blacklight may be specially designed fluorescent lamps (Figure 1), mercuryvapor lamps, light-emitting diodes (LEDs) (Figure 2), lasers, or incandescent lamps. Such sources may have several practical applications, such as diagnostic and therapeutic uses in medicine; as disinfectant in water, food, and surface treatment because of its germicidal properties; in the observation of space; in UV curing for printing, coating, and decorating objects and surfaces; and in spatial lighting effects for theatre and other entertainment applications (Pachuau and Tiwari 2008; Ahmad 2017; Dunham 2018).

Katzberg (2009) mentions three case studies of the use of this particular type of lighting in exhibition contexts. The first example refers to a museum exhibition on mineralogical specimens, in which minerals are exposed to ultraviolet lighting in order to bring out different colours. The physical principle of luminescence is transformed from an invisible phenomenon into an observable and visually stimulating experience that instructs the observer. The second example is from a solo exhibition of the German artist Regine Schumann at the Centrum Kunstlicht in de Kunst in Eindhoven (2005), in which the artist used ultraviolet light in a darkened space. On the gallery floor objects responsive to ultraviolet light were installed that appeared to float in an empty space, creating a very particular environment in order to alter viewers' perception of the space and the 
artwork. The third example refers to an exhibition of paintings by Piet Mondrian, at Harvard University's Busch-Reisinger Museum, in 2001. The paintings were submitted to an investigation in the field of conservation and restoration. The online exhibition included ultraviolet photographs of Mondrian's work that revealed changes made to the surface of the painting by both artist and conservator, thereby demonstrating the informative features that this type of lighting can bring to the interpretation of objects and surfaces.

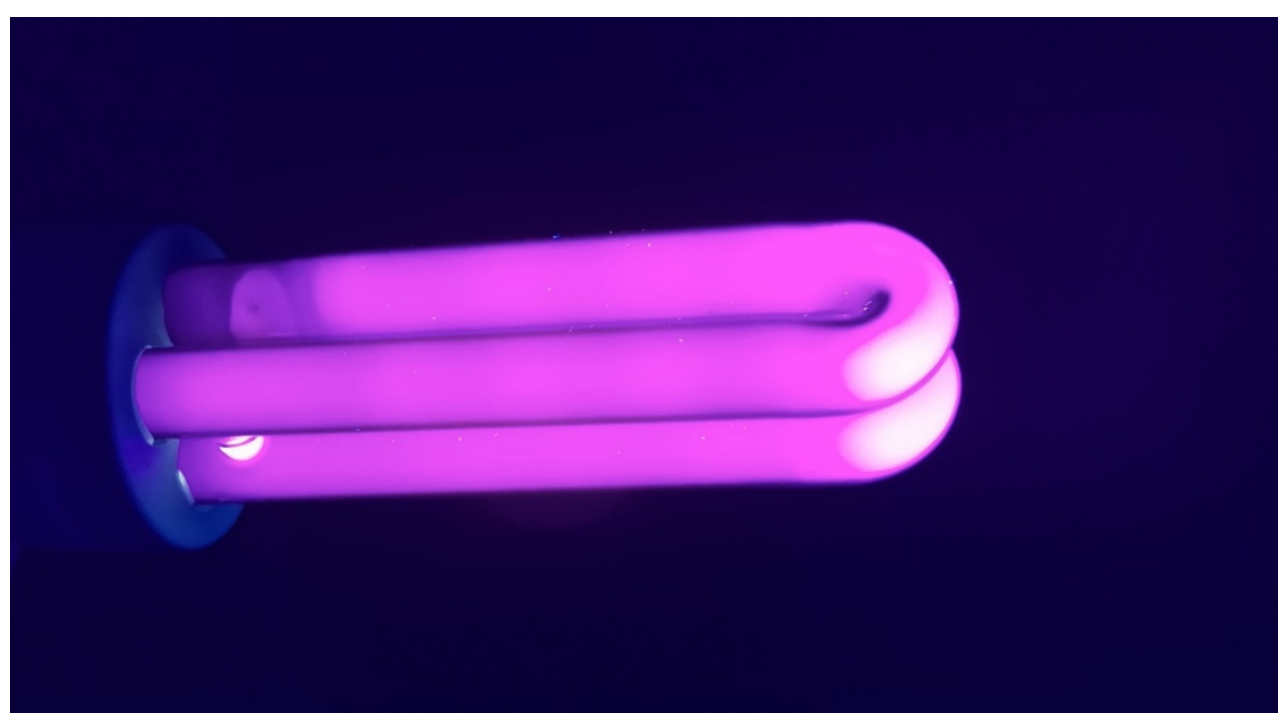

Figure 1. Compact fluorescent blacklight bulb. Author's photo.

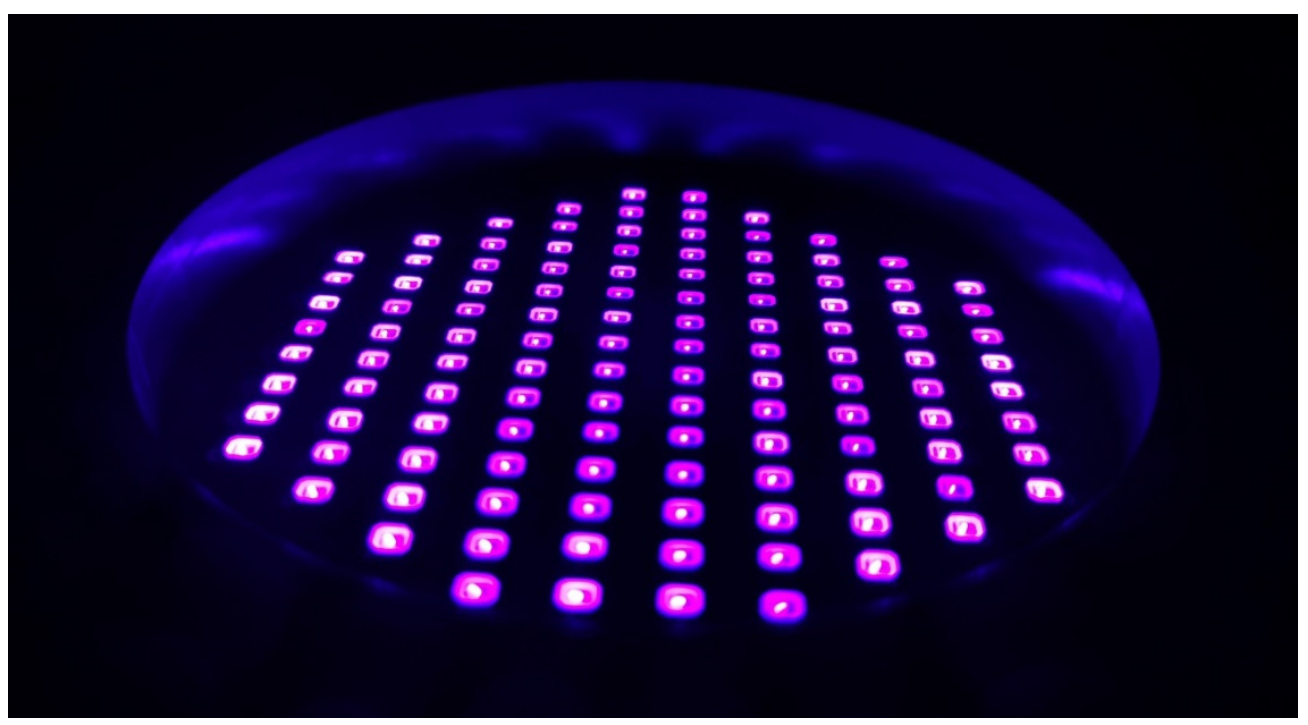

Figure 2. UV LED (light-emitting diodes). Author's photo.

\section{The Phenomenology of Luminescence}

The term "luminescenz" was first used by German physicist Eilhardt Wiedemann in 1888, and comes from the Latin words lumen, meaning light, and escentia, meaning process or state of being. Wiedemann used the term to describe all phenomena of light that are not solely conditioned by a rise in temperature (Harvey 1957, p. vii).

Light is a form of electromagnetic energy. To create light, another form of energy must be supplied. There are two common ways for this to happen: incandescence and luminescence. Incandescence is light from heat energy. Luminescence is a collective term used to describe the phenomenon of spontaneous light emission from sources other than heat, also known as "cold light," which can take place at normal and lower temperatures. 
Luminescence phenomena have fascinated mankind since the earliest times. The light from the aurora borealis, or the bioluminescence (Harvey 1920) of glow worms, fireflies, some fish, jellyfish, molluscs, fungi, and bacteria, are all examples of naturally occurring luminescence. Luminescence occurs when some form of energy excites solids, and energy is released in the form of photons (Murthy and Virk 2014). There are several types of luminescence, each named according to what the source of energy is or what the trigger for the luminescence is-for example, chemical reaction (chemiluminescence), electricity (electroluminescence), or electromagnetic radiation (photoluminescence) (Laksmanan 2007), amongst others. Photoluminescence refers to a kind of luminescence that occurs when an input of radiation energy from the ultraviolet spectrum is converted to an output of radiation energy in the visible spectrum (Addington and Schodek 2005). It consists essentially of three stages: (1) the excitation of luminescent centres, (2) the storage of excited luminescent centres, and (3) light emission.

Luminescent materials are commonly solid, inorganic materials intentionally doped with impurities such as rare earth ions, which, when excited by photons, create visible light (Ronda 2007). They are widely applied in day-to-day devices like fluorescent lamps, LED lamps, OLED emissive displays, as used in smartphones, tablets, laptops, and TV screens. Properties such as photoluminescence are widely exploited in the production of so-called smart materials, which are increasingly used in the fields of architecture and design (Ritter 2007). These materials can respond dynamically to environmental stimuli by changing their behaviour - for instance, their colour, shape, or form (Ferrara and Bengisu 2018).

Investigations of these materials have recently been carried out in several R\&D units in Portugal, with emphasis on the Faculty of Science and Technology of NOVA University of Lisbon (FCT-NOVA). This is the case of VICARTE-glass and ceramics for the arts, a research unit at the FCT-NOVA campus devoted to the promotion of transdisciplinary research applied to glass and ceramics. Although the different types of luminescent glass produced were perceived as mostly colourless in natural light, they took on the luminescence of the rare earth oxides incorporated in the glass when in the presence of ultraviolet light (Laia and Ruivo 2019). Several luminescent glasses can be produced by using different rare earth oxides: europium—red, samarium—orange, dysprosium—yellow, terbium — green, cerium — blue, and thulium—violet (Ruivo et al. 2014). Through these rare earth oxides luminescent enamels were also produced. Current research at VICARTE-Vidro e Cerâmica para as Artes, as in the project "From Inexpensive Raw Materials to New Luminescent Glass Materials" (2014), focuses on the production of new compounds, using other elements that are more accessible and sustainable than rare earth elements. The photoluminescent sulphur sodalite zeolite composite (Figure 3) is an example of this type of material. This material can be synthesized by heating $\mathrm{Na}-\mathrm{LTA}, \mathrm{NaSO}_{4}$, and $\mathrm{NaCl}$ at $900{ }^{\circ} \mathrm{C}$ under a reductive atmosphere $\left(5 \% \mathrm{H}_{2} / 95 \% \mathrm{Ar}, v / v\right)$. In such conditions, an opaque powder with photoluminescent properties is produced (Ruivo et al. 2018). This material is being studied in surface-colouring coatings for potential use in design products, lighting devices, or luminescent solar concentrators (Laia and Ruivo 2019).

From an artistic point of view, this material has been tested in order to determine whether it can be used as ink to print on glass, involving studio-based experiments and sampling (Figures 4-6) to verify the ease of adopting identical printing approaches to screen printing, intaglio, and photopolymer techniques on paper and glass (Rocha et al. 2020). 


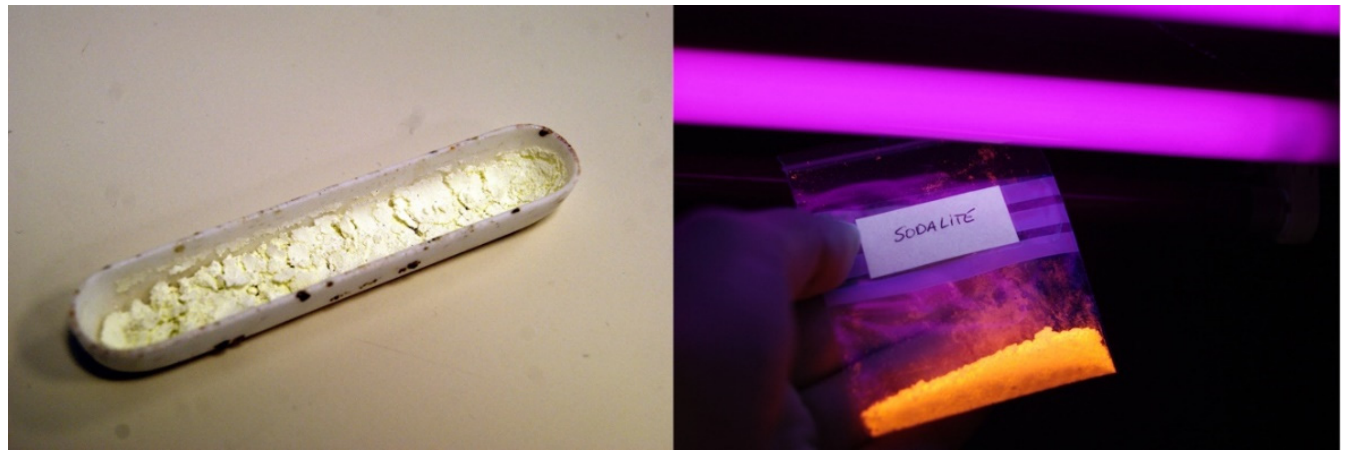

Figure 3. Aspect of sulphur sodalite zeolite composite after synthesis under visible light (left). Aspect of sulphur sodalite zeolite composite powder under $366 \mathrm{~nm}$ UV lighting (right). Author's photos. Figure created by author.

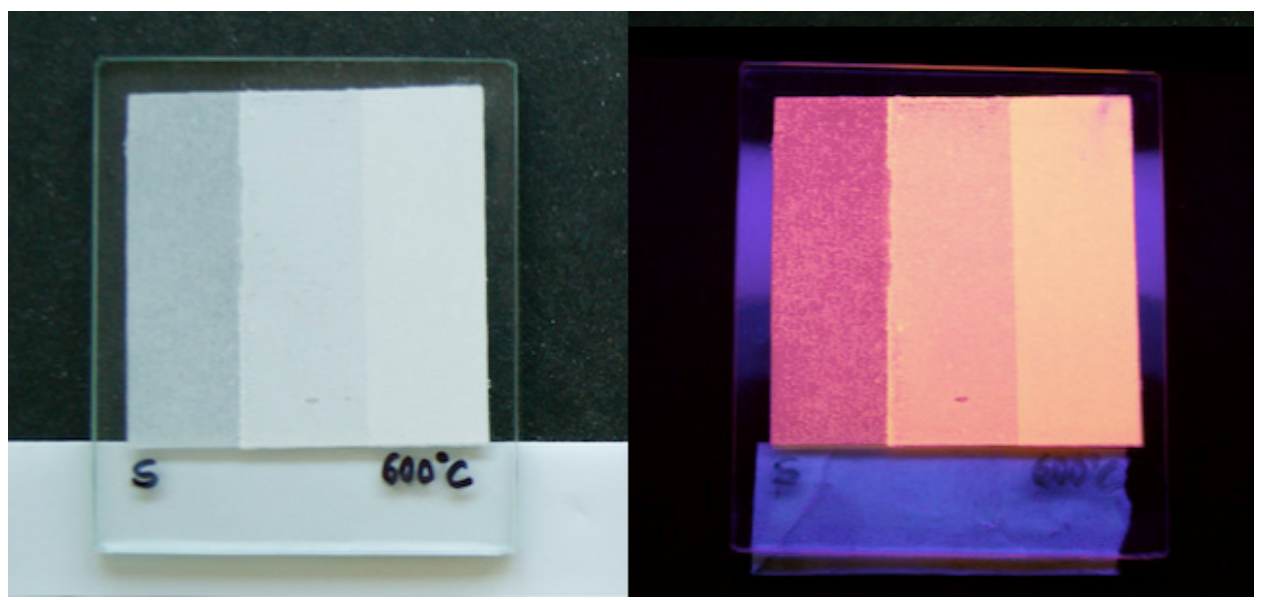

Figure 4. Screen-printed sodalite zeolite composite film depositions on glass. Sample viewed with visible light (left), sample viewed with UV light (right). Author's photos. Figure created by author.

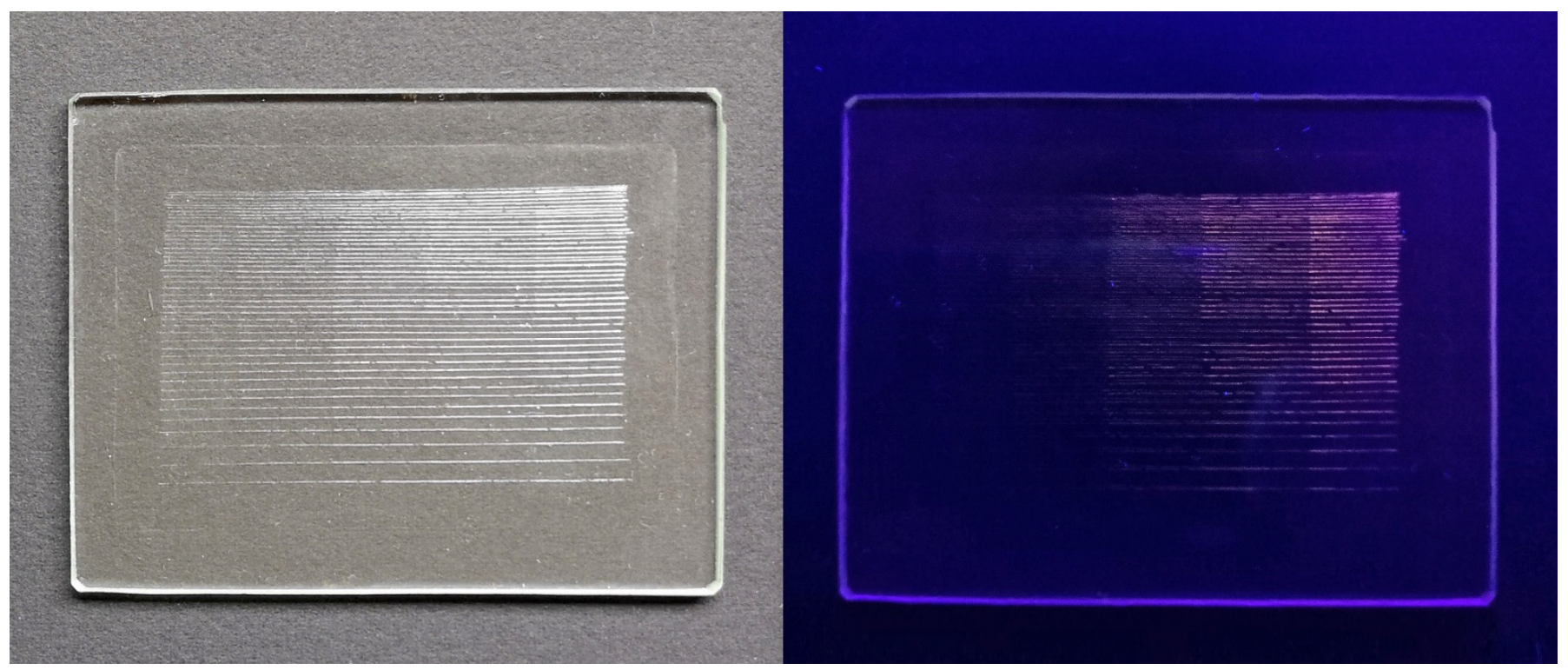

Figure 5. Line etching with sodalite zeolite composite, transfer print on glass. Sample viewed with visible light (left), sample viewed with UV light (right). Author's photos. Figure created by author. 


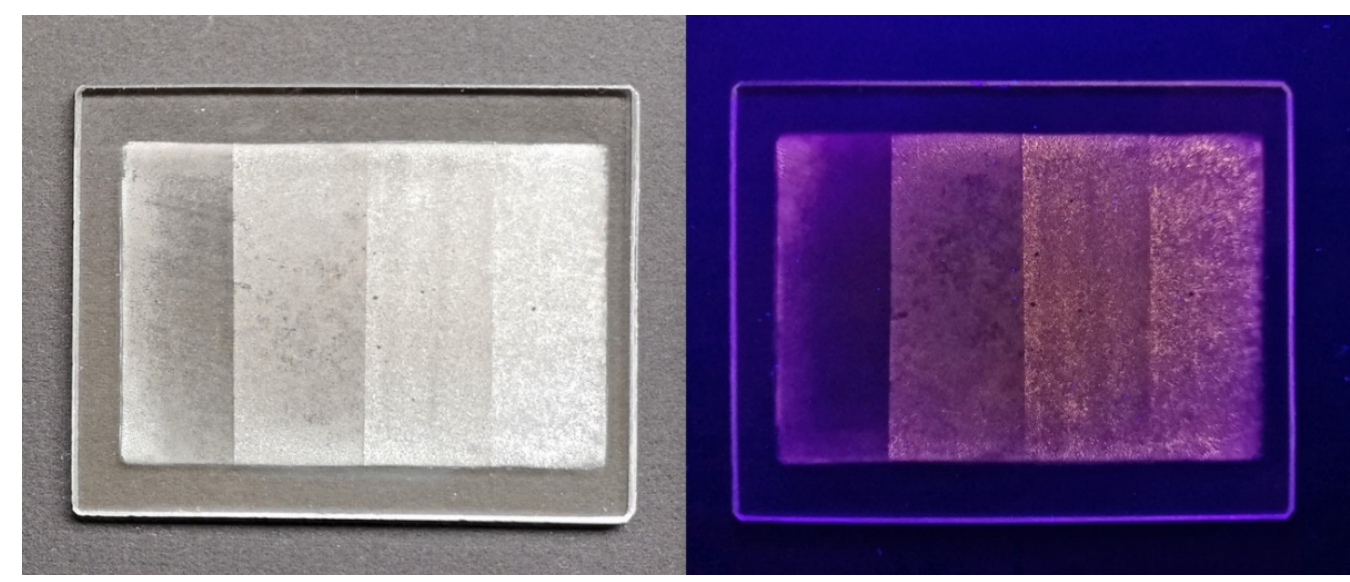

Figure 6. Aquatint etching with sodalite zeolite composite, transfer print on glass. Sample viewed with visible light (left), sample viewed with UV light (right). Author's photos. Figure created by author.

\section{The Threshold between Material and Immaterial Light: The Case of Photoluminescent Pigments}

The contemporary concern with the dematerialization of the artistic object is circumstantial to light works. Light is a medium of artistic production that challenges the limits of materiality. Artworks made since the early 1960s explore the spatial and sensory aspects of light, its aesthetics, and its immateriality. More than any other material, light fascinates artists and viewers with its luminous and intangible qualities. Because of its diaphanous character, this particular material summons opposite qualities to itself, revealing itself to be aesthetically and conceptually rich. It can create a type of volume, a bulkless volume, that can be traversed by the eye. It asks for touch when it is, in fact, the light that can touch us; that is, it can be sensed through more bodily senses than just sight. In the words of French philosopher Luce Irigaray, "I see only through the touching of light" (Irigaray 1993, p. 155). Through the language of light and photosensitivity, Irigaray builds the idea of texture of light and its corporeality, or as Catherine Vasseleu puts it, a type of carnal light (Vasseleu 1998, p. 19).

Let us go back to the aforementioned photoluminescent pigments. Photoluminescent sulphur zeolite is an opaque powder, yellowish-white in colour, that, under the influence of ultraviolet light, has the property of absorbing the photons of that light source and, in turn, emitting light within the visible spectrum: "colour emission extending between the yellow-orange, orange, and orange-red range, depending on the sulphur content" (Ruivo et al. 2018). We argue that this material has particular relevance for artists interested in working in the fields of light, colour, and perception because it manages to combine the material and the immaterial, the visual and the haptic.

Interstellar Dust in the Milky Way (2018; Figure 7) is an installation in which light is simultaneously motif, means, and material. This piece was developed from information disclosed by the European Space Agency (ESA) about the Gaia Project, which was founded to chart a three-dimensional map of the Milky Way and reveal the composition, formation, and evolution of our galaxy, including the position, distance, and motion data of nearly 1.7 billion stars. The information gathered includes brightness data on all 1.7 billion surveyed stars, their colour measurement, and how the brightness and colour change over time. The project supported the assembly of a large map, made of 234 small images screen printed on glass slides with photoluminescent sulphur zeolite enamel. The image refers to interstellar dust, which interacts with the electromagnetic radiation of the cosmos in the same way that synthesized sodalite zeolite composites interact with UV light: each of the little grains absorbing, reflecting, and re-emitting light. The piece is installed in a dark room, lit only by UV light. The visitor enters the dark room and their eyes begin a 
process of accommodation to the darkness. These are optimum conditions for gazing at the night sky.

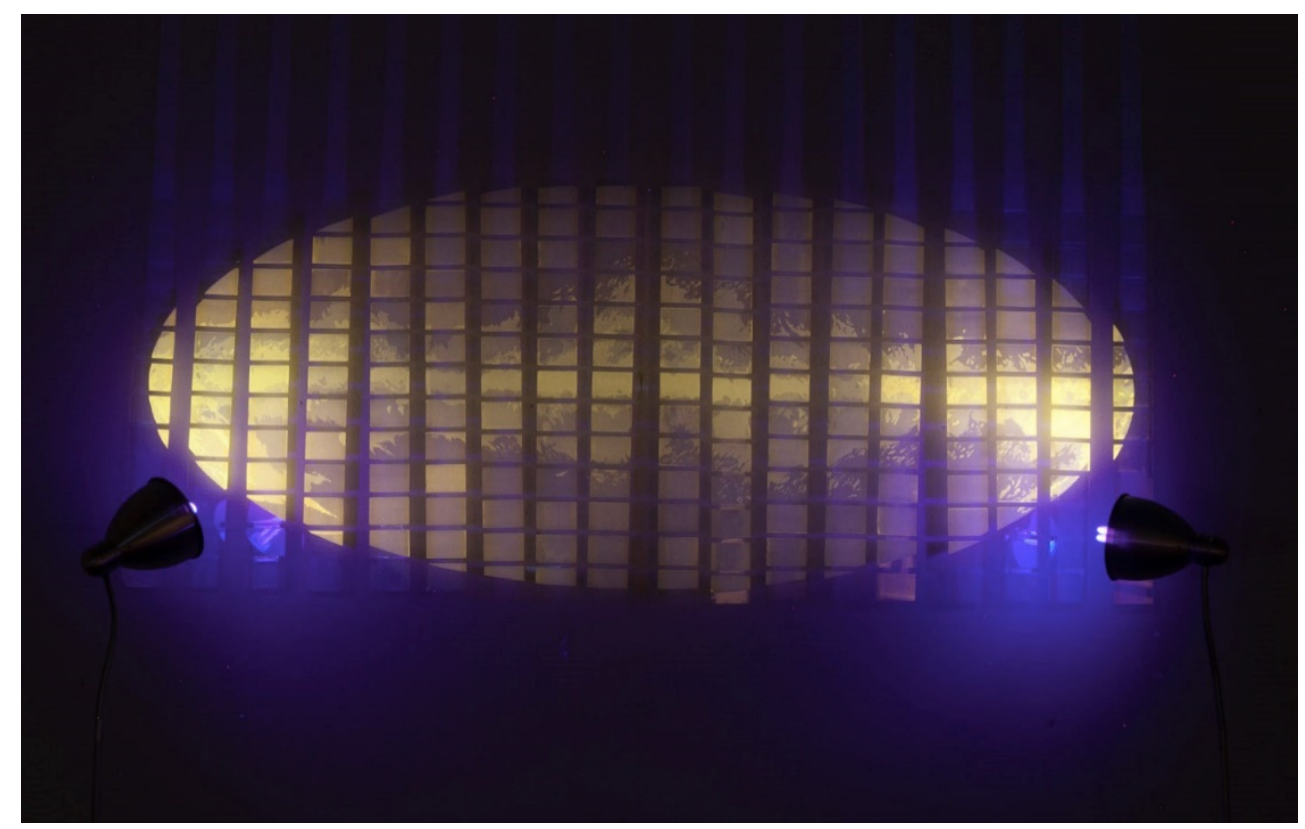

Figure 7. Interstellar Dust in the Milky Way (2018) by Ana Margarida Rocha. Screen print on glass slides, UV light. Installation in the Alberto Sampaio Museum, Guimarães, Portugal. Author's photo.

Light, or the lack of it, utterly transforms how an environment is perceived and apprehended. When we enter dark rooms after having been exposed to bright light, our eyes go through dark adaptation (Buser et al. 1992; Davson 2012). A transition from cone-operated day vision (photopic), to rod-operated night vision (scotopic), is processed to allow the eyes to see under low-light conditions, and the eyes take around $20 \mathrm{~min}$ to become attuned to darkness, as opposed to adapting to light, which is much faster (Lynch and Livingston 2001; Buser et al. 1992; Davson 2012). Human night vision is weak. The ability to perceive nocturnal landscapes, the night sky, and see in the dark is diminished because we are too used to the presence of light and pervasive illumination (Bogard 2013; Edensor 2017). However, if the eyes are kept in a low light level for some time, they grow more sensitive, and a given light will look brighter.

In "Theory of Colours" (Goethe 1840) describes perceptual experiences in dark rooms and the physiological effects of light and dark. These perceptual experiences seek to show the impact of the observer's body on the process of vision as a place of production of optical experiences. The unstable physiology and temporality of the human body are highlighted. Darkened rooms offer the possibility to feel the flow of time and our own adaptation time, and to experience the duration. To see in and with the dark is to reconfigure and expand the visual experience. The non-visual senses of touch, smell, and hearing are heightened. As Pallasmaa asserts, darkness can "dim the sharpness of vision, make depth and distance ambiguous, and invite unconscious peripheral vision and tactile fantasy" (Pallasmaa 2005, p. 46).

Luminescence is best perceived in adequate darkness. Ultraviolet light bathes the exhibition space in a purple hue, but without breaking the darkness as visible light does. A kind of performativity of light emerges, but not exactly the performativity of the cinematographic experience or the art of projection. The difference is that the beam of light is not projecting an image but rather interacting with a surface coated with light-sensitive material that, in turn, re-emits dim visible light and thus deactivates the image. A spectral, floating image increases slowly in brightness and imprints itself on the observer's retina. The initially passive and inert viewer gradually becomes immersed in the experience. 
According to Michael Rogers, these printed luminescent works are "conceptually strong in the use of glass to alter how we see and experience, as well as the intimate relationship created of the work to an individual viewer" (Almeida et al. 2019, p. 6).

In Textures of Light (Figures 8 and 9), from 2020, three phases of the rotating movement of the light from a lighthouse are depicted. The main character is the light beam. Light describes its corporeal character through a mesh texture of printed, light-sensitive pigment that shows grain and sedimentation, highlighting the haptic thickness of pigment that is also light emitting. The emitted light seems to take on a tactile quality, requiring a tactile look, an expression that Barker (2009) uses applied to cinema and that we borrow here to describe this particular visual experience. This is a light experience at the boundary between the material and immaterial, similar to that described by Lucretius on observing the movement of dust particles within a sun ray:

"Observe whenever the rays are let in and pour the sunlight through the dark chambers of houses; you will see many minute bodies in many ways through the apparent void mingle in the midst of the light of the rays, and as in never-ending conflict, skirmish and give battle, combating in troops and never halting, driven about in frequent meetings and partings ... so that you may guess from this what it is for first beginnings of things to be ever tossing about in the great void ... a small thing may give an illustration of great things and put you on the track of knowledge" (Lucretius 1995, p. 60).
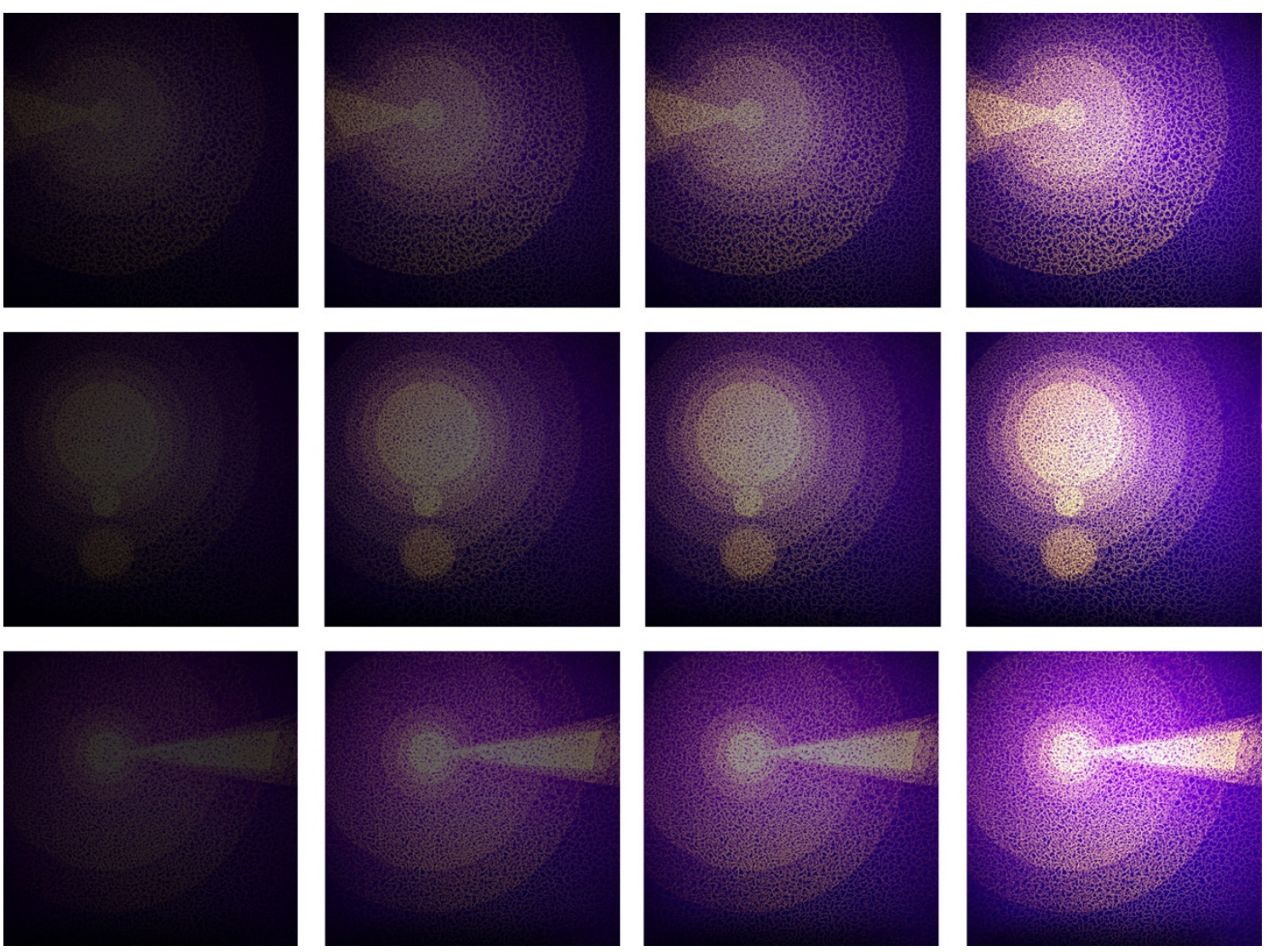

Figure 8. Textures of Light (2020) by Ana Margarida Rocha. Monotypes on Arches BFK Rives black paper. Images viewed through ultraviolet light, with a dimmer-intensity controller. Author's photos. Figure created by author. 


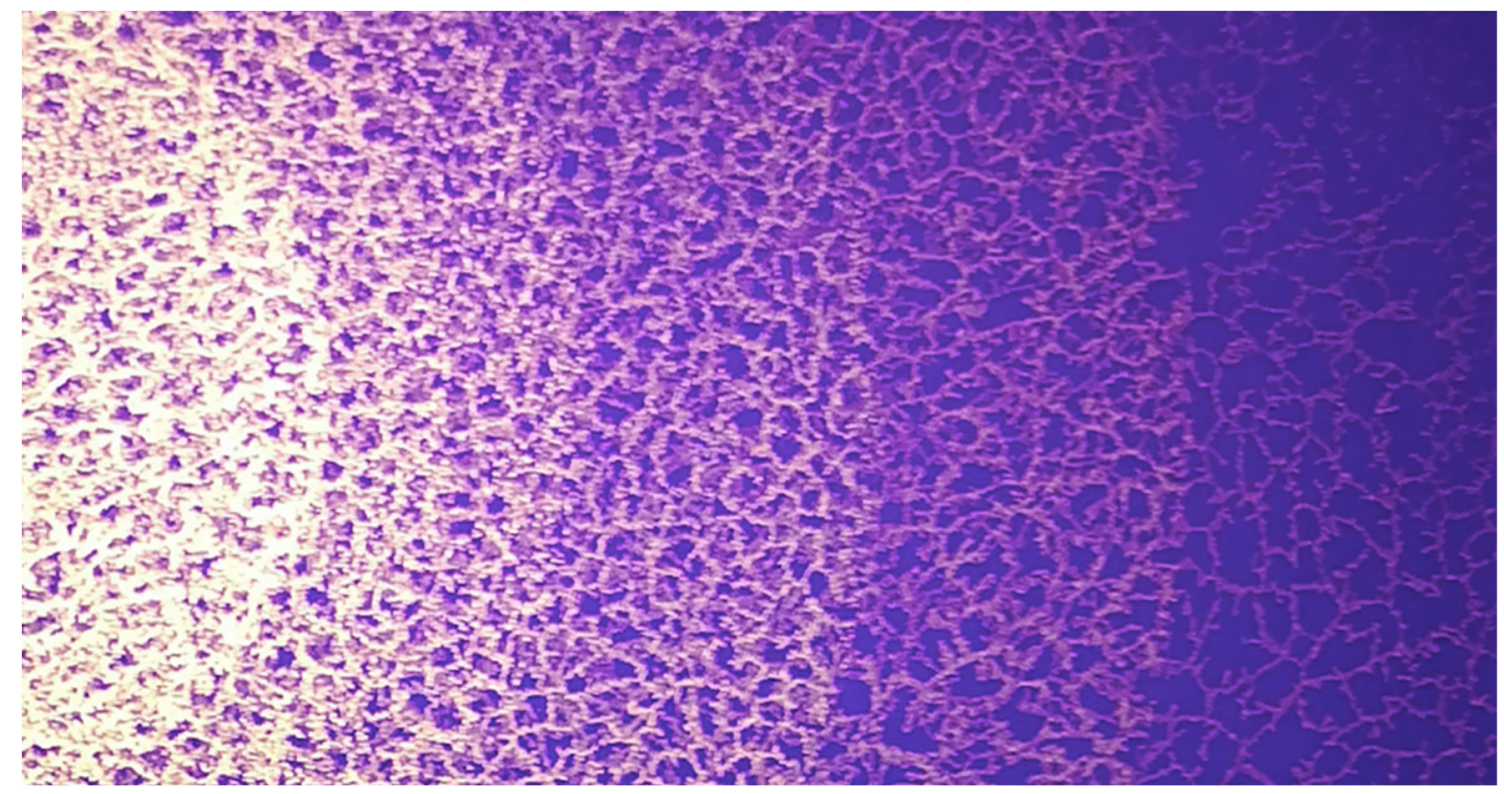

Figure 9. Textures of Light (2020) by Ana Margarida Rocha. Mesh texture detail. Author's photo.

In this particular installation, light-intensity controllers are used. Dimmers are devices used to alter the brightness of light. By changing the voltage waveform applied to the lamp, it is possible to alter the intensity of the light output (Kitsinelis 2016). This produces an expansion of time through the observer's adaptation time: the time change of light intensity and the light re-emission time from the photosensitive surface. It is possible to feel this flow of time and experience of duration not only as an external phenomenon, but also an internal one. The intensity of light entering the eye gives rise to brightness. When we speak of intensity, we are referring to the physical energy of the light, which may be measured by various kinds of photometer, but when we speak of brightness, we are referring to an experience, a quality that is measured in relation to the viewer, the effects caused within the viewer's body.

\section{Conclusions}

Sensitivity to light and the physiological and psychological effects of light on the viewer are fertile grounds for artistic practice. We argue that these light-emitting materials and pigments can combine the material and immaterial aspects of light within artworks. They allow the additive qualities of light and the subtractive qualities of the pigment to be combined. They are used as ink during the image production process, but they are also vectors of direct light emission. Creative practice must thus account for the fact that this particular material is both an illuminated surface and light itself. As ultraviolet light is shed, it emits visible light, it shines, it emanates a mesmerizing glow. The special position of brightness in the visual sphere carries a strong potential that can be exploited artistically.

Using these materials as ink effects a complete inversion of the usual process of work. Where classical processes of drawing, painting, and printing usually start with a white substrate that is progressively filled with black matter, this particular material allows for the possibility of working from a dark background that is progressively filled with radiant light matter. This material makes the light appear close to us, and it seems to take on a type of materiality.

The exhibition characteristics of these works lead the observer to question what is seen in these particular environments. First, the gallery's white cube is transformed into a black box, thus reinstating the experience of darkness. The viewer is moreover decentred, as the exhibition space is closed off, homogeneous, non-hierarchized, and level. Second, the lighting conditions are reduced to UV light, or blacklight, which does not break the darkness as visible light does, but casts a dimmed purple hue. The image, for all intents 
and purposes, remains invisible until the moment it is irradiated by UV light. After the experience of darkness follows the experience of brightness, initiating the visitor's gradual adaptation back from complete darkness. The pigment particles composing the image reemit light, a dim glow, creating the illusion of a spectral image floating in the surroundings.

The ability to control the light's intensity with dimmers indicates an ambiguity in the work, approaching the art of projection, for the time and duration associated with the experience. The photoluminescent image is transitive because it responds directly to the conditions of the environment in which it finds itself, taking into account slow changes between light and darkness. It becomes a narrative, the visual narrative of light materialization.

The way in which light-sensitive surfaces are illuminated creates a specific atmosphere during the sensual, bodily experience. Light can guide and manipulate the viewer's attention and interpretation. Working with light sources and light emission brings into play the subjective features of human vision and the direct impact of light on our bodies. Blacklight acts as a permeable and unstable mediator between the space and the viewer. Dark spaces stimulate modes of sensing space alternative to those employed in daylight, offering possibilities for developing more intimate, convivial, and focused forms of communication. Light-sensitive materials have the potential to re-establish a more sensitive and embodied contact where the eyes can also function as touch organs in an involved and explorative reflection that associates the visual with the tactile, approaching the subject, the objects, and the environment.

Author Contributions: Research developed by A.M.R., supervised by T.A. and G.M. All authors have read and agreed to the published version of the manuscript.

Funding: This research was funded by the Portuguese Foundation for Science and Technology (FCT-MCTES) through the PhD grant (SFRH/BD/125333/2016) and the Research Units VICARTE (UID/EAT/00729/2019) and LAQV-REQUIMTE (UID/QUI/50006/2019).

Institutional Review Board Statement: Not applicable.

Informed Consent Statement: Not applicable.

Data Availability Statement: Not applicable.

Conflicts of Interest: The authors declare no conflict of interest.

\section{References}

Adcock, Craig E., and James Turrell. 1990. James Turrell: The Art of Light and Space. Berkeley, Los Angeles and Oxford: University of California Press.

Addington, Michelle, and Daniel Schodek. 2005. Smart Materials and New Technologies. Amsterdam: Elsevier.

Ahmad, Shamim I. 2017. Ultraviolet Light in Human Health, Diseases and Environment. Berlin/Heidelberg: Springer.

Almeida, Teresa, Michael Rogers, and Francisco Laranjo. 2019. Exposição em Vidro e Sobre o Vidro. Porto: I2ADS. Instituto de Investigação em Arte, Design e Sociedade.

Barker, Jennifer M. 2009. The Tactile Eye: Touch and the Cinematic Experience. Berkley and Los Angeles: University of California Press. Beeson, Steven, and James W. Mayer. 2007. Patterns of Light: Chasing the Spectrum from Aristotle to LEDs. New York: Springer.

Bishop, Claire. 2005. Installation Art: A Critical History. London: Tate Publishing.

Bogard, Paul. 2013. The End of Night: Searching for Natural Darkness in an Age of Artificial Light. New York: Harper Collins Publishers.

Boyce, Peter Robert. 2014. Human Factors in Lighting, 3rd ed. Abingdon: Taylor \& Francis.

Bruce, Vicki, Mark A. Georgeson, and Patrick R. Green. 2014. Visual Perception: Physiology, Psychology and Ecology. Abingdon: Taylor \& Francis.

Bruno, Giuliana. 2014. Surface: Matters of Aesthetics, Materiality, and Media. Chicago and London: University of Chicago Press.

Buser, Pierre A., Michel Imbert, and R. H. Kay. 1992. Vision. Cambridge: MIT Press.

Clark, Robin. 2011. Phenomenal California Light, Space, Surface. Los Angeles: University of California Press.

Davson, Hugh. 2012. The Physiology of The Eye. Amsterdam: Elsevier.

Dunham, Richard E. 2018. Stage Lighting Second Edition: The Fundamentals. Abingdon: Taylor \& Francis.

Edensor, Tim. 2017. From Light to Dark: Daylight, Illumination, and Gloom. Minneapolis: University of Minnesota Press.

Ferrara, Marinella, and Murat Bengisu.. 2018. Materials that Move: Smart Materials, Intelligent Design. Berlin/Heidelberg: Springer. 
Flynn, John E. 1977. A Study of Subjective Responses to Low Energy and Nonuniform Lighting Systems. Lighting Design and Applications 7: 6-15.

Flynn, John E., Clyde Hendrick, Terry Spencer, and Osyp Martyniuk. 1979. A Guide to Methodology Procedures for Measuring Subjective Impressions in Lighting. Journal of the Illuminating Engineering Society 8: 95-110. [CrossRef]

Frercks, John E., Clyde Hendrick, Terry Spencer, and Osyp Martyniuk. 2009. Reception and discovery: The nature of Johann Wilhelm Ritter's invisible rays. Studies in History and Philosophy of Science Part A 40: 143-56. [CrossRef]

Gibson, James Jerome. 1966. The Senses Considered as Perceptual Systems. Boston: Houghton Mifflin.

Gibson, James Jerome. 1979. The Ecological Approach to Visual Perception. Boston: Houghton Mifflin.

Goethe, Johann Wolfgang. 1840. Theory of Colours. Translated by Charles Lock Eastlake. London: John Murray.

Gregory, Richard L. 2015. Eye and Brain: The Psychology of Seeing, 5th ed. Princeton: Princeton University Press.

Harvey, Edmund Newton. 1920. The Nature of Animal Light. Philadelphia and London: J.P. Lippincott Company.

Harvey, Edmund Newton. 1957. A History of Luminescence from the Earliest Times until 1900. Philadelphia: American Philosophical Society.

Irigaray, Luce. 1993. An Ethics of Sexual Difference. London: Althone.

Katzberg, Michael. 2009. Cultures of Light: Contemporary Trends in Museum Exhibition. Amsterdam: Amsterdam School for Cultural Analysis, Universiteit van Amsterdam.

Kitsinelis, Spiros. 2016. Light Sources: Technologies and Applications. Boca Raton: CRC Press.

Laia, César A. T., and Andreia Ruivo. 2019. Photoluminescent Glasses and Their Applications. In Fluorescence in Industry. Berlin and Heidelberg: Springer, pp. 365-88. [CrossRef]

Laksmanan, Arunachalam. 2007. Luminescence and Display Phosphors: Phenomena and Applications. New York: Nova Science Publishers.

Titus Lucretius Carus. 1995. On the Nature of Things: De Rerum Natura. Translated and Edited by Anthony M. Eselen. Baltimore: John Hopkins University.

Lynch, David K., and William Livingston. 2001. Color and Light in Nature. Cambridge: Cambridge University Press.

Merleau-Ponty, Maurice. 2002. Phenomenology of Perception. Translated by Colin Smith. London: Routledge.

Murthy, K. V. R., and Hardev Singh Virk. 2014. Luminescence Phenomena: An Introduction. Defect and Diffusion Forum 347: 1-34. [CrossRef]

Pachuau, Zaithanzauva, and Ramesh Chandra Tiwari. 2008. Ultraviolet Light-Its Effects and Applications. Science Vision 8: 128-36.

Pallasmaa, Juhani. 2005. The Eyes of the Skin: Architecture and the Senses. London: Wiley.

Parker, Andrew. 2003. In the Blink of an Eye: How Vision Sparked the Big Bang of Evolution. Cambridge: Perseus Pub.

Ritter, Axel. 2007. Smart Materials in Architecture, Interior Architecture and Design. Basel, Berlin and Boston: Birkhäuser.

Rocha, Ana Margarida, Graciela Machado, Teresa Almeida, César A. T. Laia, and Andreia Ruivo. 2020. Light-Emitting Prints on Glass. Bristol: IMPACT.

Ronda, Cees. 2007. Luminescence: From Theory to Applications. Weinheim: Wiley-VCH.

Ruivo, Andreia, Vania S. F. Muralha, Hugo Águas, António Pires de Matos, and César A. T. Laia. 2014. Time-Resolved Luminescence Studies of Eu3+ in Soda-Lime Silicate Glasses. Journal of Quantitative Spectroscopy and Radiative Transfer 134: 29-38. [CrossRef]

Ruivo, Andreia, Eduardo Coutino-Gonzalez, Miguel M. Santos, Wouter Baekelant, Eduard Fron, Maarten B. J. Roeffaers, Fernando Pina, Johan Hofkens, and César A. T. Laia. . 2018. Highly Photoluminescent Sulfide Clusters Confined in Zeolites. Journal of Physical Chemistry C 122: 14761-70. [CrossRef]

Vasseleu, Cathryn. 1998. Textures of Light: Vision and Touch in Irigaray, Levinas, and Merleau-Ponty. Warwick Studies in European Philosophy. London and New York: Routledge.

Wetterberg, Lennart. 2014. Light and Biological Rhythms in Man. Amsterdam: Elsevier. 